\title{
The Effect of Combined Growth Hormone and a Gonadotropin-Releasing Hormone Agonist Therapy on Height in Korean 3-M Syndrome Siblings
}

\author{
In Kyung Lee ${ }^{1}$, Han Hyuk Lim ${ }^{1}$, and Yoo-Mi Kim² \\ ${ }^{1}$ Department of Pediatrics, College of Medicine, Chungnam National University, Chungnam National University Hospital, Daejeon; \\ ${ }^{2}$ Department of Pediatrics, College of Medicine, Chungnam National University, Chungnam National University Sejong Hospital, Sejong, Korea.
}

\begin{abstract}
3-M syndrome is a rare autosomal recessive growth disorder characterized by severe growth retardation, low birth weight, characteristic facial features, and skeletal anomalies, for which three causative genes (CUL7, OBSL1, and CCDC8) have been identified. We herein report two Korean siblings with 3-M syndrome caused by two novel OBSL1 mutations, and describe the effect of a combined treatment with growth hormone (GH) and a gonadotropin-releasing hormone (GnRH) agonist. A 7-year-old girl with short stature (-3.37 standard deviation score, SDS) and breast budding presented with subtle dysmorphic features, including macrocephaly, frontal bossing, a triangular face, prominent philtrum, full lips, a short neck, and fifth-finger clinodactyly. GnRH stimulation test revealed a pubertal pattern and advanced bone age of 8 years and 10 months. Her older sister, aged 10 years and 9 months, had experienced an early menarche, and had an advanced bone age (13.5 years) and predicted adult height of $142 \mathrm{~cm}$ (-4.04 SDS). Targeted exome sequencing identified that the siblings had two heteroallelic mutations in OBSL1. Both siblings underwent a combination therapy with GH and a GnRH agonist. A height gain was noted in both siblings even after short-term treatment. To fully elucidate the effects of the combined therapy, a larger cohort should be analyzed following a longer treatment period. However, such an analysis would be challenging due to the rarity of this disease.
\end{abstract}

Key Words: Short stature, precocious puberty, growth hormone, 3-M syndrome, OBSL1

\section{INTRODUCTION}

First described by Miller, McKusick, and Malvaux in 1975, ${ }^{1} 3-\mathrm{M}$ syndrome (MIM 273750, 612921, and 614205) is a rare autosomal recessive growth disorder characterized by severe growth retardation, low birth weight, characteristic facial features, and skeletal anomalies. ${ }^{1-4}$ This syndrome is mainly caused by lossof-function mutations in the genes encoding cullin 7 (CUL7),

Received: June 12, 2020 Revised: August 27, 2020

Accepted: September 14, 2020

Corresponding author: Yoo-Mi Kim, MD, PhD, Department of Pediatrics, College of Medicine, Chungnam National University, Chungnam National University Sejong Hospital, 20 Bodeum 7-ro, Sejong 30099, Korea.

Tel: 82-44-955-4757, Fax: 82-44-995-3070, E-mail: ym4805@gmail.com

-The authors have no potential conflicts of interest to disclose.

(C) Copyright: Yonsei University College of Medicine 2020

This is an Open Access article distributed under the terms of the Creative Commons Attribution Non-Commercial License (https://creativecommons.org/licenses/ by-nc/4.0) which permits unrestricted non-commercial use, distribution, and reproduction in any medium, provided the original work is properly cited. obscurin-like 1 (OBSL1), and coiled-coil domain containing 8 (CCDC8) proteins. ${ }^{2,3,5}$ Any defect in these causative genes (CUL7, $O B S L 1$, or $C C D C 8$ ) leads to pre- and postnatal growth failure due to resistance to the growth hormone (GH) and insulin-like growth factor (IGF) axes. ${ }^{1-3}$ However, the detailed mechanism underlying the growth impairment associated with 3-M syndrome remains to be elucidated..$^{1-4}$ We herein report two precociously pubertal Korean sisters with 3-M syndrome caused by two novel heteroallelic OBSL1 mutations.

\section{CASE REPORT}

A 7-year-old girl (Case 1) with short stature and early breast budding visited our clinic. She was born with a weight of $2.74 \mathrm{~kg}$ at 38 weeks of gestation (10-25th percentile, -1.45 standard deviation score, SDS). Her height at birth was $46 \mathrm{~cm}$ (-2.52 SDS). The heights of her father and mother were $167 \mathrm{~cm}$ (-1.1 SDS) and $143 \mathrm{~cm}$ (-3.8 SDS), respectively, and her mother had expe- 
rienced her menarche at 11 years of age. The midparental height was estimated at $148.5 \mathrm{~cm}(-2.55$ SDS $)$. The girl had a height of $108.6 \mathrm{~cm}$ (-3.37 SDS), body weight of $21.5 \mathrm{~kg}$ (-0.38 SDS), head circumference of $50 \mathrm{~cm}(-0.37 \mathrm{SDS})$, and arm span of $109 \mathrm{~cm}$. She did not have a goiter. She had Tanner-stage-II breasts, whereas her pubic hair was of Tanner stage I. She presented with macrocephaly, frontal bossing, a triangular face, prominent philtrum, full lips, a short neck, fifth-finger clinodactyly, and prominent heels (Fig. 1). Nevertheless, she had no developmental issues, except that her bone age (BA) was advanced to 8 years and 10 months (height for BA: -5.11 SDS). Skeletal survey revealed lumbar lordosis, brachydactyly, and a narrowed pelvic cavity (Fig. 2). Laboratory tests for chemistry and thyroid hormone showed normal levels. The serum IGF-1 and IGF-binding protein-3 (IGFBP-3) levels were $232.0 \mathrm{ng} / \mathrm{mL}$ (0.1 SDS) and $4670 \mathrm{ng} / \mathrm{mL}$ (3.5 SDS), respectively. GH provocation test showed normal peak GH levels (10.3 and $18.9 \mathrm{ng} / \mathrm{mL}$ ), and gonadotropin-releasing hormone $(\mathrm{GnRH})$ stimulation test revealed a pubertal pattern (luteinizing hormone peak: 10.7 IU/L). Her karyotype was also normal.
Her older sister (Case 2, 10 years and 9 months of age) visited our clinic with a concern of early menarche. She had experienced menarche when she was 9 years and 10 months old. She was born with a weight of $2.82 \mathrm{~kg}$ (50-75th percentile, -1.26 SDS) at 36 weeks of gestation. Her facial features resembled those of her younger sister, and the typical prominent heel form was observed (Fig. 1). Her height, weight, and head circumference at presentation were $137 \mathrm{~cm}$ (0.01 SDS), $44 \mathrm{~kg}$ (0.97 SDS), and $54.5 \mathrm{~cm}$ (2.58 SDS), respectively. Breasts and pubic hair were of Tanner stages IV and III, respectively. Her BA was advanced to 13 years and 6 months (height for BA: -3.03 SDS), and her predicted adult height was $142 \mathrm{~cm}(-4.04 \mathrm{SDS})$ as per the Greulich-Pyle criteria.

Targeted exome sequencing was performed to assess for genetic abnormalities. Genetic testing revealed two heteroallelic mutations (transheterozygosity) in OBSL1 (NM_015311.2) c.2135-3_2135-2del and c.3341G>A (p.Trp1114*) (Fig. 3A). It should be noted that this is the first time these two mutations have been identified in patients with 3-M syndrome. The population allele frequencies of c.2135-3_2135-2del and c.3341G>A
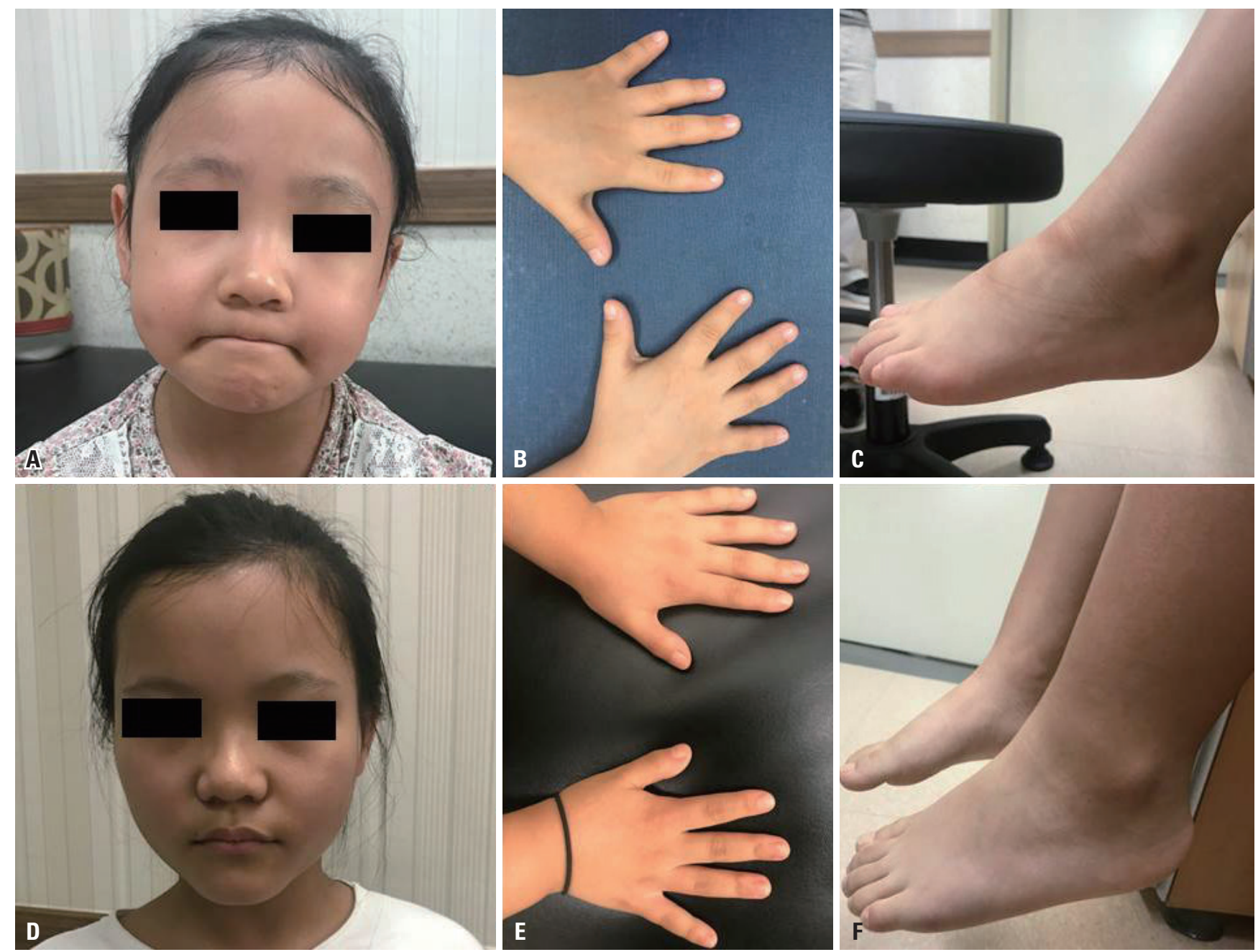

Fig. 1. Clinical photos of (A-C) Case 1 and (D-F) Case 2, showing typical features of 3-M syndrome. A and D: Photos showing frontal bossing, a triangular face, prominent philtrum, a fleshy nose, and full lips. B and E: Photos showing fifth-finger clinodactyly. C and F: Photos showing prominent heel. 

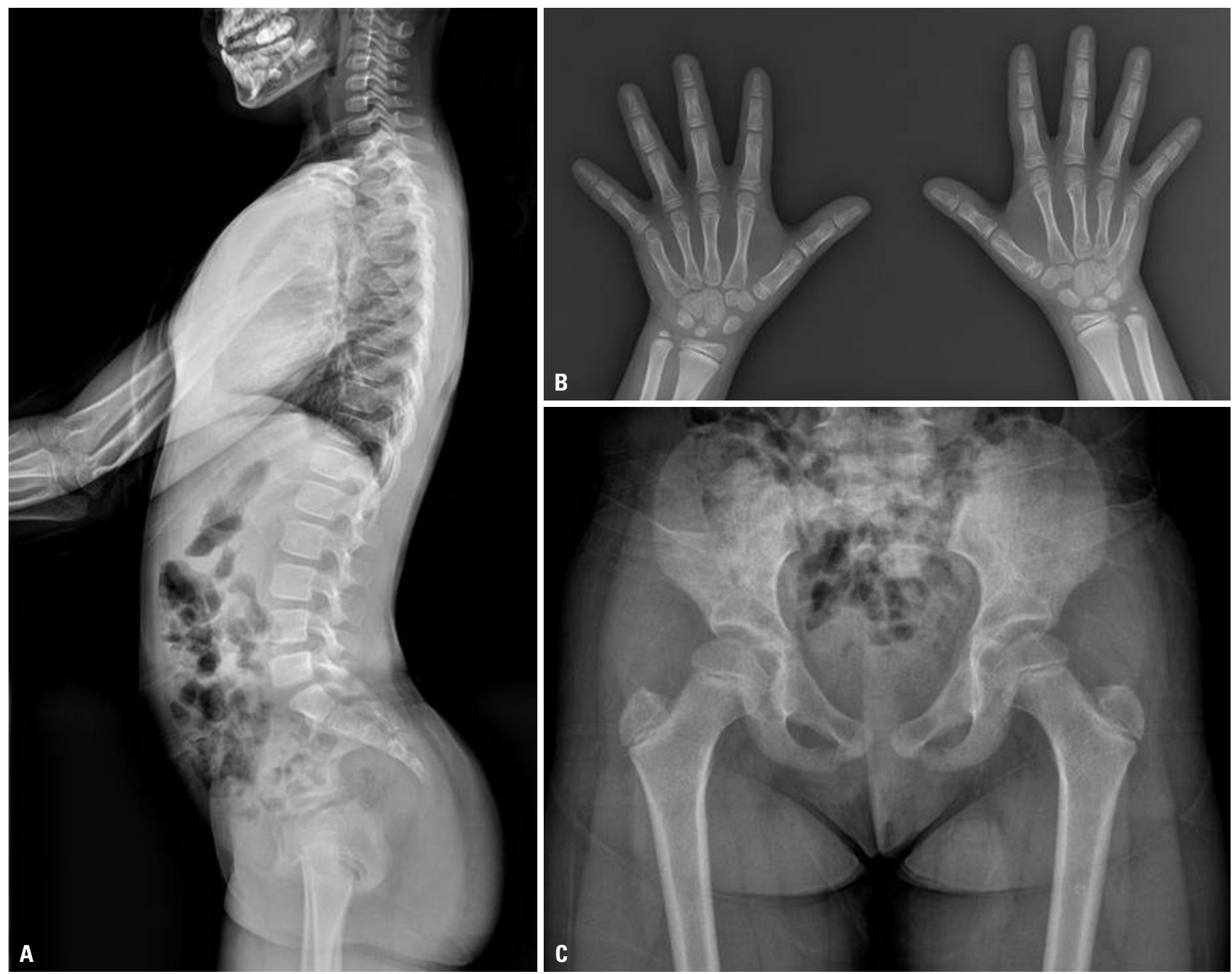

Fig. 2. Simple radiographs of Case 1 with 3-M syndrome showing $(A)$ hyperlordosis, $(B)$ advanced bone age and brachydactyly, and (C) narrowing pelvic cavity.

(p.Trp1114*) are reported as 0.0006 and 0.0001 in the Genome Aggregation Database (gnomAD, http://gnomad.broadinstitute.org/), respectively.

The two sisters showed central precocious puberty, which occurred incidentally independent of 3-M syndrome. To date, no association between 3-M syndrome and precocious puberty has been reported. Despite the central precocious puberty, the sisters were treated with GH and a GnRH agonist for their pathological short stature and precocious puberty. Following 22 months of combination therapy with GH and GnRH (at 9 years and 8 months of age), the height gain of Case 1 was 12.6 cm (height: $121.2 \mathrm{~cm},-2.3 \mathrm{SDS}$ ), and her BA was advanced to 10.5 years (height for BA: -2.91 SDS). Case 2, on the other hand, received 3 months of GH therapy alone, and then 6 months of the combination therapy with $\mathrm{GH}$ and $\mathrm{GnRH}$ agonist. Although the age of Case 2 was over the optimal age for $\mathrm{GnRH}$-agonist therapy, we nevertheless subjected her to this therapy to delay the menarche and lengthen the GH treatment duration. After 9 months, her height gain was $4 \mathrm{~cm}$ (height: $141 \mathrm{~cm}$ ), and her
BA was advanced to 14 years (height for BA: -2.86 SDS). The doses of $\mathrm{GH}$ and $\mathrm{GnRH}$ agonist were $0.27 \mathrm{mg} / \mathrm{kg} /$ week and $11.75 \mathrm{mg} / 12$ weeks, respectively.

After the combination therapy, height SDS values for the BA of Case 1 and 2 improved from -5.11 and -3.03 to -2.91 and -2.86 , respectively.

Informed consent was obtained from the patients regarding the reporting and publication of this case report. Since this was not a clinical trial and no off-label drugs were used, the ethical approval is not required for this case report.

\section{DISCUSSION}

We identified novel heteroallelic (compound heterozygous) mutations of OBSL1 [NM_015311.2; c.2135-3_2135-2del and c.3341G>A (p.Trp1114*)] in two Korean sisters with short statures and precocious puberty. Among the three causative genes of 3-M syndrome, CUL7 accounts for $77.5 \%$, OBSL1 for $16.3 \%$, 
and $C C D C 8$ for less than $5 \%$ of the cases. ${ }^{5-8}$ To date, only 38 patients with 3-M syndrome and 24 OBSL1 variants have been reported., ${ }^{27-14}$ In total, seven missense, two splicing, and 15 small deletion/insertion mutations have been identified. These mutations reside within the first eight exons encoding the Ig domains of OBSL1 proteins (Fig. 3B). OBSL1 is a homolog of the c.2135-3_2135-2del (splicing) c.3341G>A (p.Trp1114*)

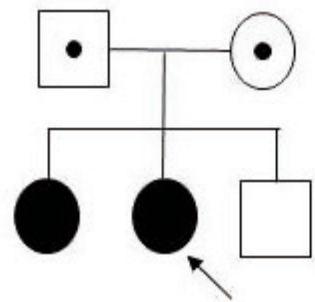

NM_015311.2 (OBSL1):c.3341G>A (p.Trp1114Ter)

Reference

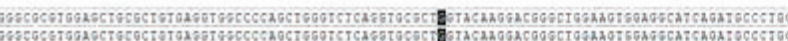
sequence

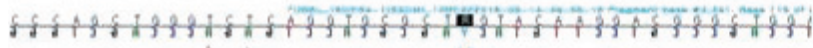

Patient

Mother

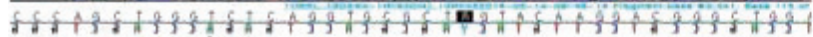

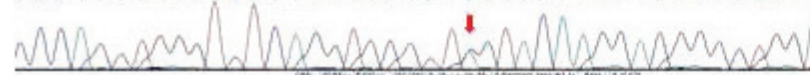

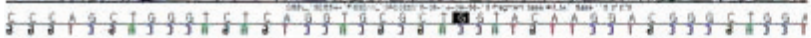

Father

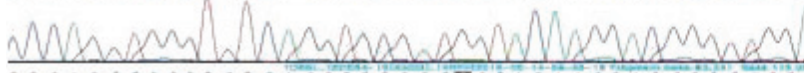

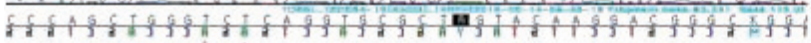
Sister

A

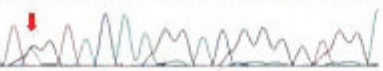

NM_015311.2 (OBSL 1):c.2135-3_2135-2del (splicing)

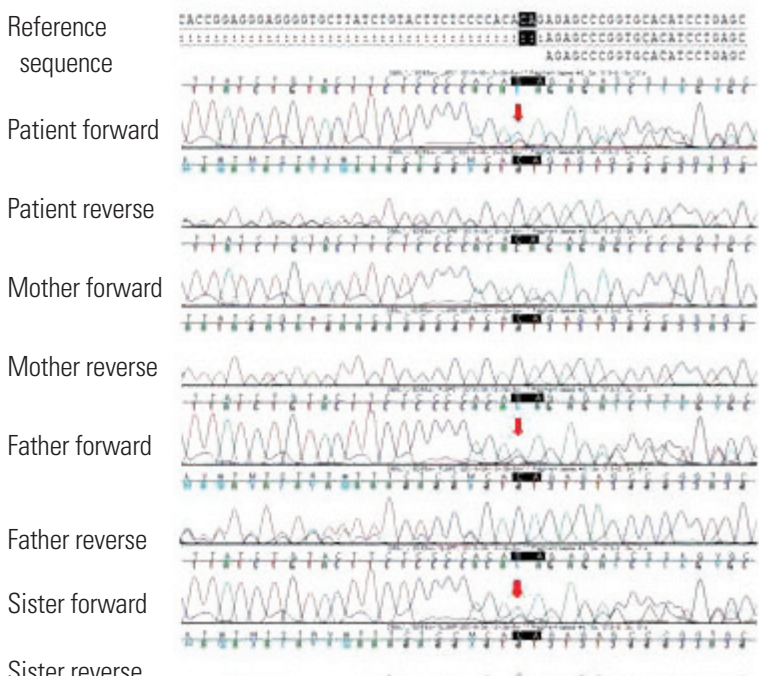

Sister reverse

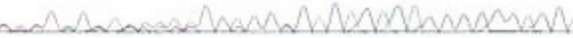
c.2135-3_2135-2de
In this study
c.3341G $>A\left(p . T r p 1114^{*}\right)$

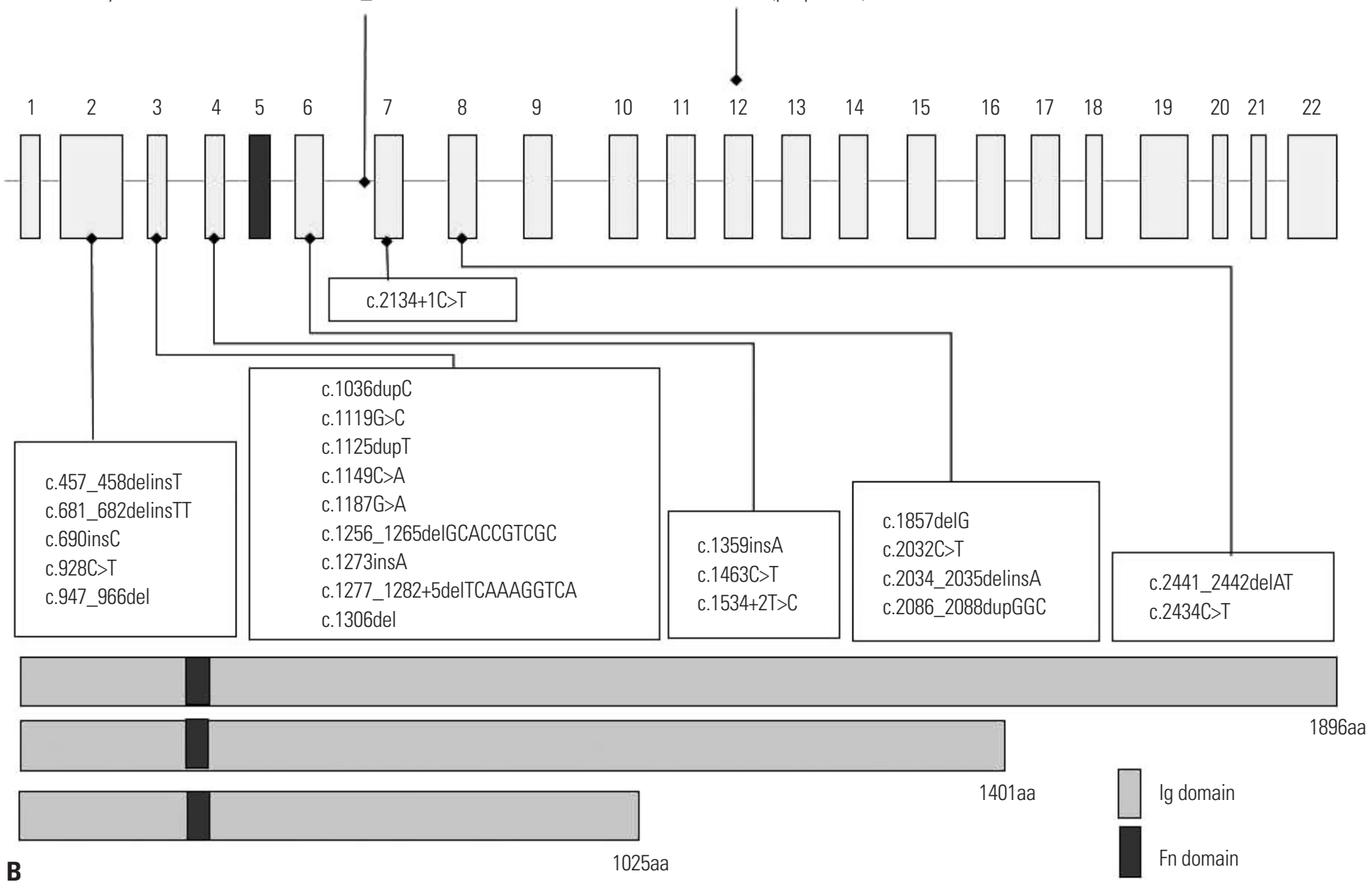

Fig. 3. Partial genomic DNA sequences of OBSL1 (NM_015311.2) both (A) in this study and (B) in previously reported mutations. 
muscle protein obscurin, ${ }^{3}$ which contributes to growth retardation by modulating the expression of IGFBPs (IGFBP-2 and IGFBP-5) and downregulating CUL7.,3

Patients with 3-M syndrome exhibit significantly different height SDS values depending on the mutation (-5.7, -4.7, and -4.1 for CUL7, OBSL1, and CCDC8, respectively). ${ }^{2,4,11}$ However, the effects of $\mathrm{GH}$ treatment on the symptoms caused by these three different mutations are still unknown, and only a few cases have been reported. Keskin, et al. ${ }^{11}$ have reported the case of a 16-month-old girl who was small for a gestational age girl [67 cm tall (-3.6 SDS)] and had a homozygous p.T45Nfs*40 (c.1273 dupA) mutation in the OBSL1 gene. After 6 months of treatment with $\mathrm{GH}$ at a dose of $0.25 \mathrm{mg} / \mathrm{kg} /$ week, a growth increment of $7 \mathrm{~cm}$ was achieved.

In this study, we treated our patients with GH and a GnRH agonist, whereby a height gain and decreased rate of bone advancement were achieved. Further studies involving longer treatments and larger cohorts are needed to fully elucidate the effect of the combination therapy with a GnRH agonist and GH on 3-M syndrome.

\section{ACKNOWLEDGEMENTS}

We would like to thank the patients and their family for participating in this study. We also wish to thank Green Cross genome for providing the genetic result.

\section{AUTHOR CONTRIBUTIONS}

Conceptualization: Yoo-Mi Kim. Data curation: In Kyung Lee and Yoo-Mi Kim. Formal analysis: all authors. Funding acquisition: YooMi Kim. Investigation: In Kyung Lee and Yoo-Mi Kim. Methodology: In Kyung Lee and Yoo-Mi Kim. Project administration: Yoo-Mi Kim. Resources: Yoo-Mi Kim. Software: In Kyung Lee. Supervision: Yoo-Mi Kim. Validation: Yoo-Mi Kim. Visualization: In Kyung Lee and Yoo-Mi Kim. Writing_original draft: In Kyung Lee and Yoo-Mi Kim. Writing-review \& editing: Yoo-Mi Kim and Han Hyuk Lim. Approval of final manuscript: all authors.

\section{ORCID iDs}

$\begin{array}{ll}\text { In Kyung Lee } & \text { https://orcid.org/0000-0002-4962-3810 } \\ \text { Han Hyuk Lim } & \text { https://orcid.org/0000-0002-5297-5913 } \\ \text { Yoo-Mi Kim } & \text { https://orcid.org/0000-0002-8440-5069 }\end{array}$

\section{REFERENCES}

1. Clayton PE, Hanson D, Magee L, Murray PG, Saunders E, Abu-
Amero SN, et al. Exploring the spectrum of 3-M syndrome, a primordial short stature disorder of disrupted ubiquitination. Clin Endocrinol (Oxf) 2012;77:335-42.

2. Hanson D, Murray PG, Coulson T, Sud A, Omokanye A, Stratta E, et al. Mutations in CUL7, OBSL1 and CCDC8 in 3-M syndrome lead to disordered growth factor signalling. J Mol Endocrinol 2012;49:267-75.

3. Hanson D, Murray PG, Black GC, Clayton PE. The genetics of 3-M syndrome: unravelling a potential new regulatory growth pathway. Horm Res Paediatr 2011;76:369-78.

4. Huber C, Munnich A, Cormier-Daire V. The 3M syndrome. Best Pract Res Clin Endocrinol Metab 2011;25:143-51.

5. Hanson D, Murray PG, O'Sullivan J, Urquhart J, Daly S, Bhaskar $\mathrm{SS}$, et al. Exome sequencing identifies CCDC8 mutations in 3-M syndrome, suggesting that CCDC8 contributes in a pathway with CUL7 and OBSL1 to control human growth. Am J Hum Genet 2011; 89:148-53.

6. Huber C, Delezoide AL, Guimiot F, Baumann C, Malan V, Le Merrer $\mathrm{M}$, et al. A large-scale mutation search reveals genetic heterogeneity in 3M syndrome. Eur J Hum Genet 2009;17:395-400.

7. Al-Dosari MS, Al-Shammari M, Shaheen R, Faqeih E, Alghofely MA, Boukai A, et al. 3M syndrome: an easily recognizable yet underdiagnosed cause of proportionate short stature. J Pediatr 2012; 161:139-45.

8. Hanson D, Murray PG, Sud A, Temtamy SA, Aglan M, SupertiFurga A, et al. The primordial growth disorder 3-M syndrome connects ubiquitination to the cytoskeletal adaptor OBSL1. Am J Hum Genet 2009;84:801-6.

9. Huber C, Fradin M, Edouard T, Le Merrer M, Alanay Y, Da Silva $\mathrm{DB}$, et al. OBSL1 mutations in 3-M syndrome are associated with a modulation of IGFBP2 and IGFBP5 expression levels. Hum Mutat 2010;31:20-6.

10. Demir K, Altıncık A, Böber E. Severe short stature due to 3-M syndrome with a novel OBSL1 gene mutation. J Pediatr Endocrinol Metab 2013;26:147-50.

11. Keskin M, Muratoğlu Şahin N, Kurnaz E, Bayramoğlu E, Savaş Erdeve Ş, Aycan Z, et al. A rare cause of short stature: 3M syndrome in a patient with novel mutation in OBSL1 gene. J Clin Res Pediatr Endocrinol 2017;9:91-4.

12. Simsek-Kiper PO, Taskiran E, Kosukcu C, Arslan UE, Cormier-Daire V, Gonc N, et al. Further expanding the mutational spectrum and investigation of genotype-phenotype correlation in $3 \mathrm{M}$ syndrome. Am J Med Genet A 2019;179:1157-72.

13. Guo MH, Shen Y, Walvoord EC, Miller TC, Moon JE, Hirschhorn $\mathrm{JN}$, et al. Whole exome sequencing to identify genetic causes of short stature. Horm Res Paediatr 2014;82:44-52.

14. Akawi NA, Ali BR, Hamamy H, Al-Hadidy A, Al-Gazali L. Is autosomal recessive Silver-Russel syndrome a separate entity or is it part of the 3-M syndrome spectrum? Am J Med Genet A 2011; 155A:1236-45. 